\title{
Experimental Study on Impermeability of Recycled Concrete
}

\author{
Shao Zhen WANG, Jian Gong YANG, Lu WEI \\ Tianjin College, University of Science and Technology Beijing, Tianjin, 301830, China
}

\begin{abstract}
Recycled concrete is a kind of concrete which is constructed by crushing and removing the building waste and concrete blocks and mixing them according to a certain proportion after grading. In this study, the applicability of recycled concrete is studied only in terms of impermeability.
\end{abstract}

\section{Introduction}

Under the background of protecting environment, saving resources and harmonious development of human and nature, recycled concrete is bred. Recycled concrete is the construction waste to be broken, classified according to a certain proportion, used for coarse aggregate of concrete, so as to replace the original natural aggregate. There are many factors affecting the concrete, the applicability of recycled concrete is studied only in the aspect of impermeability.

\section{Experimental ideas}

The micro factor that affects the impermeability of concrete is cracks in the concrete. To enhance the impermeability of recycled concrete, it is necessary to reduce the internal cracks. The influencing factors of the impermeability of recycled concrete can be studied by means of the control variable method, such as sand ratio, replacement rate, water cement ratio, etc. A gradient test designed for influencing factors under the conditions of the specification.

Calculation formula of impermeability grade:

$$
S=10 H-1
$$

$\mathrm{S}$ : Impermeability grade of recycled concrete;

$\mathrm{H}$ : The water pressure at the top of the recycled concrete specimen when it has seepage 。

Notes: 1、Concrete impermeability grade is divided into $S_{4}, S_{6}, S_{8}, S_{10}, S_{12}$, If pressurized to $1.2 \mathrm{MPa}$,
After 8 hours, it is still impervious to water, then stop the test, the impermeability of the test piece is indicated by $\mathrm{S}_{12}$.

2、According to the calculation of anti permeability grade, if the maximum water pressure value $\mathrm{H}$ is even, then the calculated $\mathrm{S}$ value is odd, at this time $\mathrm{S}-1$ is the impermeability grade, for example: $\mathrm{H}=0.8 \mathrm{MPa}, \mathrm{S}=7$, then the impermeability grade is $\mathrm{S}_{6}$.

The anti permeability level take calculation formula of impermeability coefficient:

$$
K=a D^{2} /(2 \times T \times H)
$$

$\mathrm{K}$ : relative impermeability coefficient, unit $\mathrm{cm} / \mathrm{s}$;

D: average water penetration height, unit $\mathrm{cm}$;

$\mathrm{H}$ : the pressure of water is expressed as the height of water, unit cm;

T: constant pressure time, unit s;

$a$ : water absorption rate of recycled concrete.

Water absorption formula:

$a=\left(m_{0} / m\right) \times 100 \%$

$\mathrm{m}_{0}$ : The quality of non absorbent, unit $\mathrm{g}$;

$\mathrm{m}$ : quality after water absorption unit $\mathrm{g}$.

Notes: Impermeability grade and impermeability coefficient are different, impermeability coefficient is used in hydraulic concrete, relative permeability coefficient is calculated by reference seepage height. In this test, the anti - permeability instrument is a step-up anti-seepage instrument, so the formula of the impermeability grade is selected.

\section{Experimental instruments}




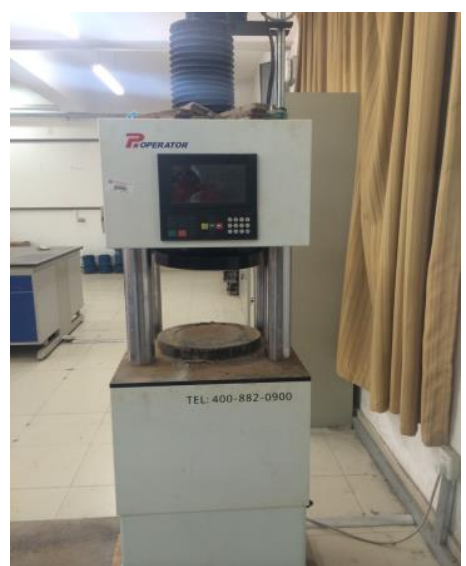

DY-2008MC Full automatic pressure testing machine

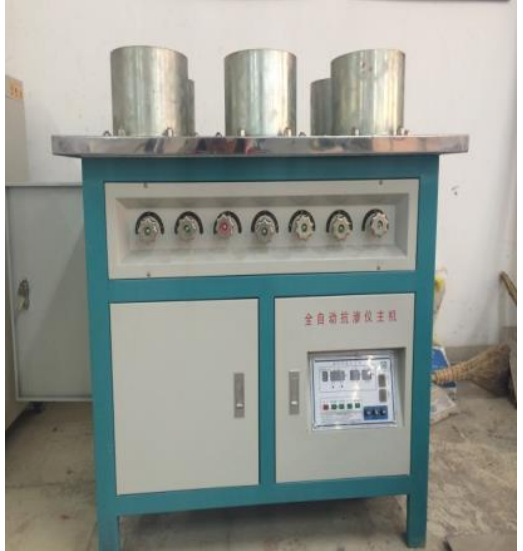

HP-4.0 Full automatic compression concrete impermeability tester

\section{Materials selection}

Choose suitable construction waste as the test coarse aggregate, because the waste concrete requires the machine to break it, artificial fragmentation can not be achieved. In addition, the manufacturing of asphalt materials and sintered brick materials of concrete, under the same condition, the impermeability of sintered brick materials better than asphalt brick materials, also the strength of concrete and asphalt material is shortage, so this experiment selects sintered brick as coarse aggregate of recycled concrete.

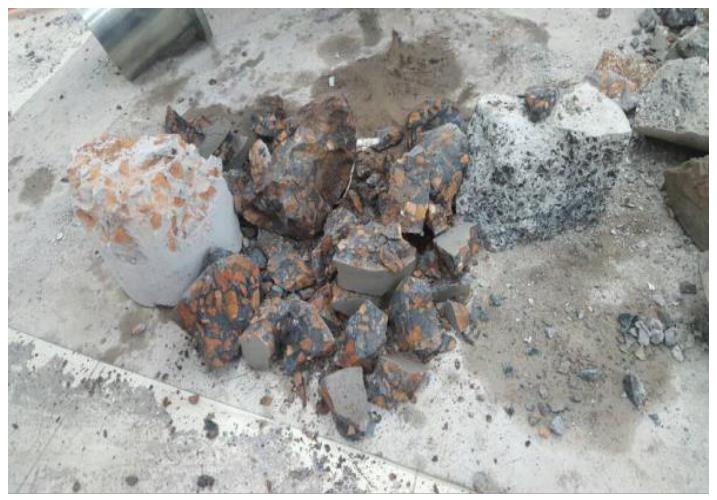

\section{5 experimental dates}

The recycled concrete strength grade in this experiment is $\mathrm{C} 30$, the pressure increase $\mathrm{v}$ be equal to $0.0125 \mathrm{Mpa} / \mathrm{h}$, initial pressure $0.3 \mathrm{MPa}$, the impermeability grade is $\mathrm{S}_{4}$, a total of five specimens of each test group, each group of 3 specimens, each gradient experiments were performed two times. Test results are shown in table 1 and table 2 . Comparison of the results of the two tests is shown in figure 1-figure 4 .

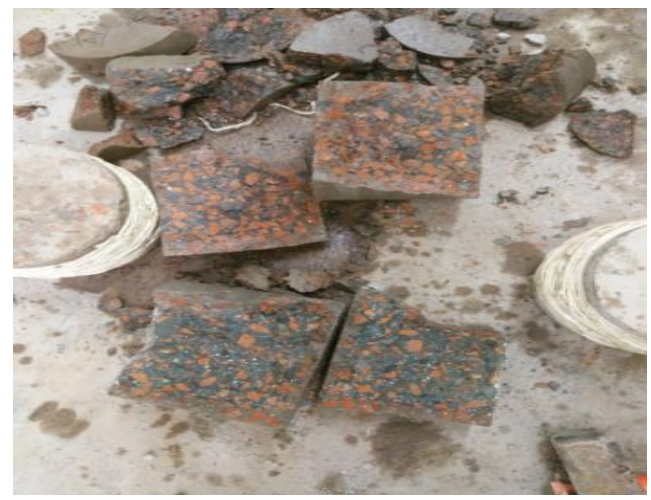

Table 1 Water cement ratio and sand rate, impermeability gradient test results

\begin{tabular}{|c|c|c|c|c|c|c|}
\hline \multirow{2}{*}{ Specimen } & \multirow{2}{*}{$\begin{array}{c}\text { Water cement } \\
\text { ratio }\end{array}$} & \multicolumn{2}{|c|}{ Average pressure (Mpa) } & \multirow{2}{*}{$\begin{array}{c}\text { Sand } \\
\text { rate }(\%)\end{array}$} & \multicolumn{2}{|c|}{ Average pressure (Mpa) } \\
\cline { 3 - 6 } & The first time & $\begin{array}{c}\text { The second } \\
\text { time }\end{array}$ & & The first time & $\begin{array}{c}\text { The second } \\
\text { time }\end{array}$ \\
\hline The 1 group & 0.4 & 0.538 & 0.546 & 30 & 0.488 & 0.483 \\
\hline The 2 group & 0.44 & 0.467 & 0.446 & 32 & 0.538 & 0.521 \\
\hline The 3 group & 0.5 & 0.433 & 0.446 & 33 & 0.479 & 0.467 \\
\hline The 4 group & 0.56 & 0.429 & 0.434 & 34 & 0.480 & 0.471 \\
\hline The 5 group & 0.58 & 0.442 & 0.438 & 35 & 0.475 & 0.47 \\
\hline
\end{tabular}

Table 2 Test results of substitution rate and content of fly ash against seepage gradient

\begin{tabular}{|c|c|c|c|c|c|c|}
\hline \multirow{2}{*}{ Specimen } & \multirow{2}{*}{$\begin{array}{c}\text { Substitution } \\
\text { rate (\%) }\end{array}$} & \multicolumn{2}{|c|}{ Average pressure (Mpa) } & \multirow{2}{*}{$\begin{array}{c}\text { Fly ash } \\
\text { content }\end{array}$} & \multicolumn{3}{|c|}{ Average pressure (Mpa) } \\
\cline { 5 - 7 } & & The first time & The second time & $(\%)$ & $\begin{array}{c}\text { The first } \\
\text { time }\end{array}$ & The second time \\
\hline The 1 group & 100 & 0.454 & 0.463 & 0 & 0.51 & 0.525 \\
\hline The 2 group & 75 & 0.463 & 0.454 & 15 & 0.504 & 0.492 \\
\hline The 3 group & 50 & 0.559 & 0.559 & 30 & 0.567 & 0.563 \\
\hline
\end{tabular}




\begin{tabular}{|l|c|c|c|c|c|c|}
\hline The 4 group & 25 & 0.554 & 0.542 & 45 & 0.525 & 0.525 \\
\hline The 5 group & 0 & 0.471 & 0.463 & 60 & 0.463 & 0.450 \\
\hline
\end{tabular}

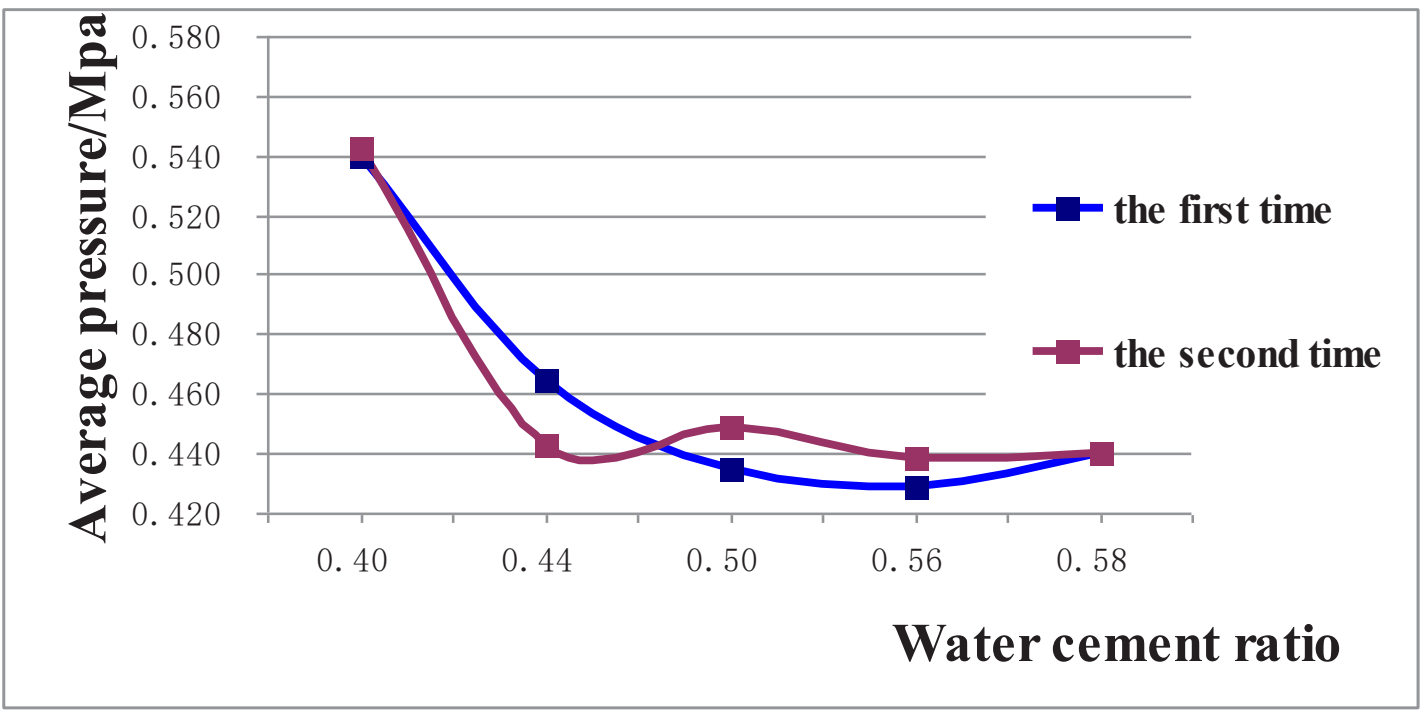

Figure 1 Comparison of gradient test results of water cement ratio

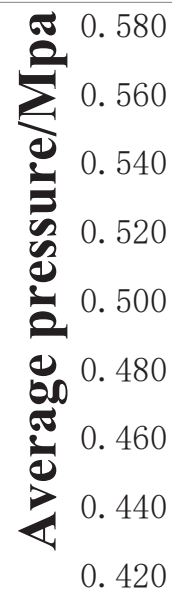

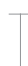

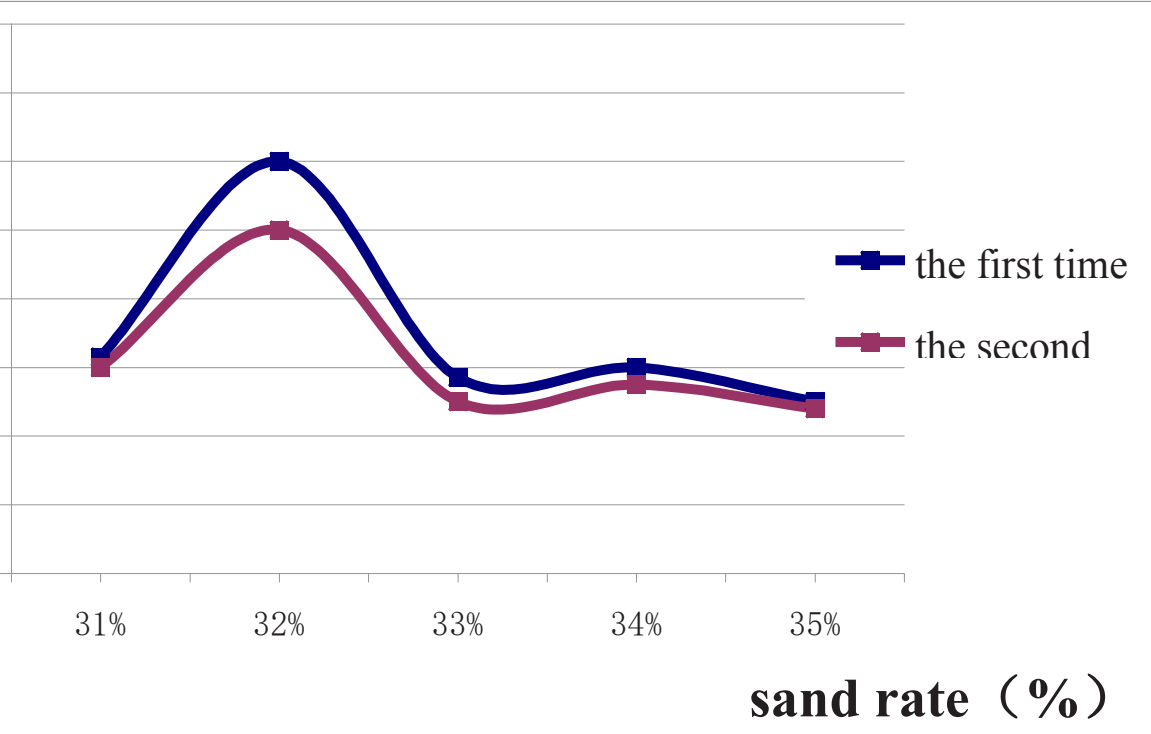

Figure 2 sand rate test results of water cement ratio 


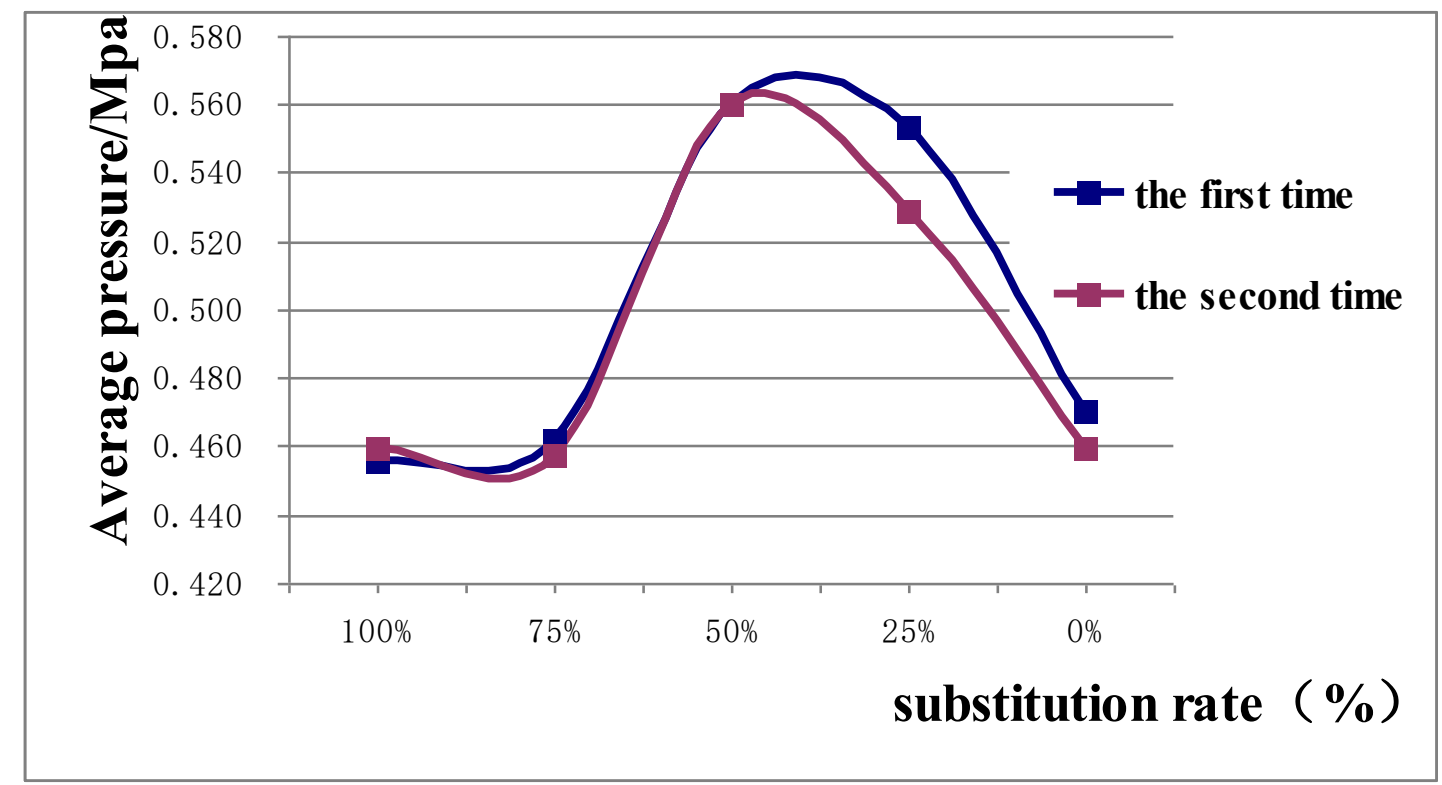

Figure 3 substitution rate results of water cement ratio

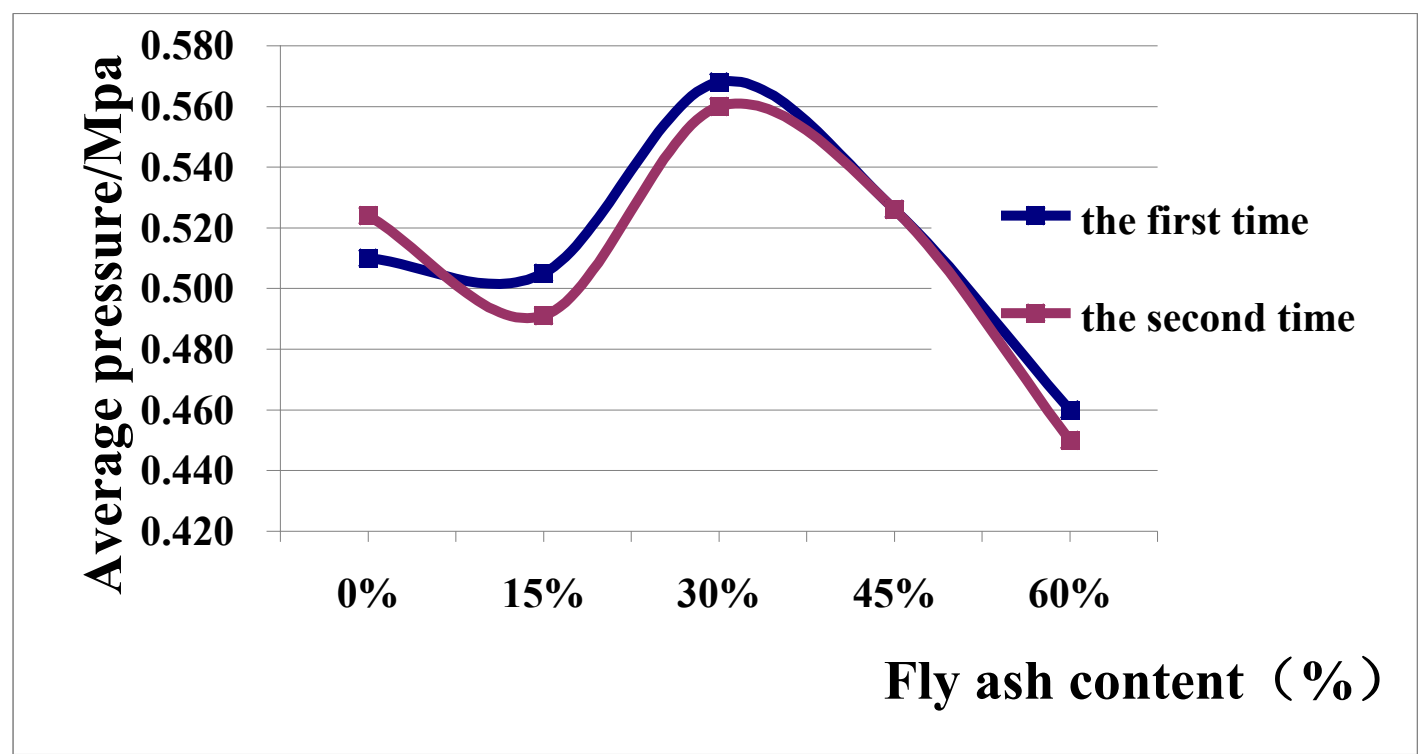

Figure 4 fly ash Volume test results of water cement ratio

\section{Conclusions}

1. From the water cement ratio data, it can be seen that when the other conditions are unchanged, when the water cement ratio is 0.4 , the seepage resistance pressure is the largest. With the increase of water cement ratio, the resistance to seepage pressure decreases continuously. Therefore, the water cement ratio is controlled at about 0.4 , which can improve the impermeability of recycled concrete.

2. From the sand rate data, it is found that when the sand rate is about $32 \%$, the impermeability pressure of recycled concrete is the maximum.

3. From the data of substitution rate, it can be seen that when the substitution rate is about $50 \%$, the maximum impermeability pressure is observed. Therefore, adding 50\% natural aggregate to the waste aggregate can not only improve the impermeability of recycled concrete, but also save the cost effectively.

4. From the data of the fly ash, it can be seen that the pressure decreases when the fly ash is greater than $30 \%$. Therefore, when the content of fly ash is about $30 \%$, the impermeability of recycled concrete can be appropriately improved.

The test shows that the impermeability of recycled concrete can be improved by controlling the water cement ratio, sand rate, replacement rate of recycled aggregate and adding admixtures. But because of the particularity of recycled concrete itself, the crack inside the aggregate can not be avoided. Therefore, it is suggested that from the macroscopic and microcosmic two angles, it is a new direction to study how to remedy the cracks produced by recycled aggregate effectively. 


\section{References}

1. Zhang Zhen, Lou Zongke, Zhang Yingxue. Study on permeability resistance of recycled aggregate concrete based on orthogonal experiment. China rural water conservancy and Hydropower 2016.10.15.

2. Zhang Haobo, Ren Huichao, Kou Jialiang. Fly ash on the experimental study on the compressive strength and durability of recycled concrete. Journal of Xi'an University of technology.2016.12.30.

3. Wei Chengjuan, Gao Hui, Xue Pengfei, Dong Huifang. Experimental study on durability of recycled aggregate concrete. Construction technology.2015.12.28.

4. Yue Gongbing, Li Qiuyi, Gao Song. The quality of recycled fine aggregate replacement rate and effect on the frost resistance of concrete. Journal of natural disasters. 2015.10.15.

5. Chen Yungang; Xiao Jian Zhuang; Sun Zhenping. The recycled coarse aggregate concrete durability test. Journal of Anhui University of Technology (NATURAL SCIENCE EDITION).2013.7.15.

6. Geng Jian; Sun Jiaying; Mo Liwei; Zhang Guoliang. Microstructure characteristics of recycled fine aggregate and its concrete. Civil engineering and environmental engineering.2013.4.15.

7. Jing Xinpei; Shu Qian; Dong Yunting. Rich brick grain test the impermeability of recycled concrete. Journal of Lanzhou University of Technology.2017.3.3.

8. Qin Li, Ding Jingnan, Zhu Jinsong. Test on impermeability and frost resistance of high volume fly ash and slag high strength concrete. Chinese Journal of agricultural engineering.2017.3.23. 